\title{
A Great Improvement of Fusion Efficiency in Mouse B Cell Hybridoma Production by Use of the New Culture Medium, GIT
}

\author{
Toshio Kudo, Rimi Morishita, ${ }^{*}$ Rika Suzuki (Seno) $\dagger$ \\ and Takehiko Tachibana* \\ Clinical Immunology Section, College of Medical Sciences, \\ Tohoku University, Sendai 980, *Department of \\ Immunology, Research Institute for Tuberculosis and \\ Cancer, Tohoku University, Sendai 980, and †Clinical \\ Diagnosis Laboratory, Suzuki Memorial Hospital, \\ Iwanuma 989-24
}

Kudo, T., Morishita, R., Suzuki (Seno), R. and Tachibana, T. A Great Improvement of Fusion Efficiency in Mouse B Cell Hybridoma Production by Use of the New Culture Medium, GIT. Tohoku J. exp. Med., 1987, 153 (1), 55-66 - The recently established culture medium, GIT, is applicable to many kinds of cells including mouse and human myeloma cells, and most adhesive cell lines. We applied this GIT medium to mouse B cell hybridoma production. When the medium was used to propagate myeloma cells before cell fusion and also for HAT selective medium, the fusion efficiency was more than twice as high as when the regular medium (RPMI-1640 supplemented with FBS) was used. Constantly more than $80 \%$ wells were hybridoma positive irrespective of the antigens used. To determine the optimal cell concentration at the hybridoma selection, a graded number of myeloma and spleen cells was distributed to each well ; the best result was obtained when $3 \times 10^{4}$ myeloma and $3 \times 10^{5}$ spleen cells were distributed to each well. In addition, the GIT medium shows very little lot-to-lot variation. These results indicate that fusion efficiency in mouse B cell hybridoma production was greatly improved by using GIT medium. —_ hybridoma production; GIT medium; monoclonal antibody

Since Köhler and Milstein (1975) introduced a new technology to obtain a monoclonal antibody directed against a single epitope on an antigen, monoclonal antibodies have been used extensively. The production of monoclonal antibodies to various antigens by the fusion of antigen-sensitized spleen cells with myeloma cells has been expanded to every biological field. Though basic methods have been well established, there is still a need for the more effective, stable fusion efficiency. Good and constant fusion efficiency makes it possible to effectively establish desired hybridoma clones and contributes markedly to the progress of

Received July 2, 1987 ; accepted for publication July 28, 1987. 
science. Many improvements of fusion technology has been achieved but some unsatisfactory aspects still remain (Westerwoudt 1985).

We had a chance to use the recently established GIT medium and found that it produced an extraordinarily good growth of myeloma cells, and subsequently used the medium to produce hybridoma. GIT medium, which was developed as an all-purpose culture medium by Sasai (Takeda Chemical Industries, Ltd., Hikari ; Sasai et al. 1985), is applicable to many kinds of cells including mouse and human myeloma cells, and most adhesive cell lines. When this medium was used not only to propagate myeloma cells before cell fusion, but also as the basis of the selective medium for hybridoma production, a great improvement of fusion efficiency was observed, compared with even the best results obtained by the regular method using fetal bovine serum (FBS). Constantly more than $80 \%$ of the seeded wells produced hybridoma colonies in GIT and the production of antibody in GIT was about twice as high as in the regular medium.

In this paper, we report the experimental results on fusion efficiency, and emphasize the usefulness of the GIT medium as the excellent medium for hybridoma production.

\section{Materials and Methods}

Myeloma cells. P3X63Ag8-653, a BALB/c non-secretory myeloma cell line (HGPRT less), given to us by Dr. Okumura, Juntendo Medical College, Tokyo, was routinely maintained in RPMI-1640 (GIBCO Lab., Chagrin Falls, OH, USA) containing 10\% heatinactivated fetal bovine serum (lot No. 378 , Bocknek, Rexdale, Ontario, Canada) at $37^{\circ} \mathrm{C}$ in a humidified atmosphere of $5 \% \mathrm{CO}_{2}$ and $95 \%$ air. In the present experiments, the myeloma cells were also cultured in the GIT medium (Wako Pure Chemical Industries, Ltd., Osaka). The cell growth in the two media was compared.

Immunization. 8-12 week old $\mathrm{BALB} / \mathrm{c}$ female mice were inoculated intraperitoneally with a human $\mathrm{T}$ cell line (Hut $78,1 \times 10^{6}$ ) once a week for three weeks. A final ip inculation was administered on the fourteenth day following the third injection. Three days later, the spleen was removed and dissociated by mincing. In another series of experiments, BALB/c mice were inoculated ip with $0.2 \mathrm{ml}$ of $5 \%$ sheep red blood cells (SRBC) by the same schedule as used for the Hut 78 cells.

Cell fusion. The spleen cells from the immunized mice were isolated and washed with serum free-RPMI 1640 medium three times and mixed with washed myeloma cells at a ratio of $10: 1$. After centrifugation at $300 \times \mathrm{g}$ for $10 \mathrm{~min}, 1 \mathrm{ml}$ of fusion solution, made of $2 \mathrm{~g}$ of PEG 1000 (165-09085, Wako Pure Chemical Industries Ltd.), $2 \mathrm{ml}$ of RPMI 1640, and 0.2 $\mathrm{ml}$ of DMSO (B-10-4, No. 134-45, Nakarai Chemicals Ltd., Kyoto), was gradually added to the cell pellet. The cells were kept at $37^{\circ} \mathrm{C}$ for $1 \mathrm{~min}$, and diluted with warm RPMI 1640 at a rate of $2 \mathrm{ml} / \mathrm{min}$ for $5 \mathrm{~min}$. After centrifugation at $200 \times \mathrm{g}$ for $10 \mathrm{~min}$ at room temperature, the fused cells were resuspended in either GIT or RPMI 1640 supplemented with $10 \%$ FBS at a concentration of $5 \times 10^{6} / \mathrm{ml}$ spleen cells and $5 \times 10^{5} / \mathrm{ml}$ myeloma cells. In some cases, the cell concentration was changed.

Fused cell suspension $(0.2 \mathrm{ml})$ was distributed into each well of a 96 -well culture plate. Incubation was carried out at $37^{\circ} \mathrm{C}$ in a $5 \% \mathrm{CO}_{2}$ incubator for $24 \mathrm{hr}$ and then the cells were refed with the hybridoma selective medium.

Selective medium. For selective medium (GIT-HIAT, HIAT means HAT plus insulin) for hybridoma production, the GIT medium was supplemented with 2-mercaptoethanol (2- 
ME, $2 \mathrm{mM})$, L-glutamine $(2 \mathrm{mM})$, penicillin (100 U/ml), streptomycin $(100 \mu \mathrm{g} / \mathrm{ml})$, insulin (I,10 $10^{-3} \mathrm{U} / \mathrm{ml}$, Shimizu Pharmaceuticals, Shimizu), dihydroxyethylglycine (DHEG, $1.8 \mathrm{mg}$ / $\mathrm{ml}$, Dojindo Laboratories, Kumamoto), and 1/50 volume of HAT concentrated solution (Flow Laboratories, McLean, VA, USA, 16-808-49. 50 $\times$ HAT solution was made of 5,000 $\mu \mathrm{M}$ hypoxanthin, $20 \mu \mathrm{M}$ aminopterine, and $800 \mu \mathrm{M}$ thymidine). Another selective medium, FBS-HIAT, was composed of RPMI 1640 plus $10 \%$ FBS instead of GIT medium; other chemicals were added as in the case of GIT-HIAT.

GIT medium. The recently established culture medium, GIT medium, was purchased

TABle 1. Composition of GIT medium (mg/liter)

\begin{tabular}{|c|c|c|c|}
\hline GFS* & 3000 & Inositol & 12.60 \\
\hline Insulin & 2.00 & Nicotinamide & 2.0185 \\
\hline Transferrin & 2.00 & Pyridoxal hydrochloride & 2.000 \\
\hline Ethanolamine & 0.122 & Pyridoxine hydrochloride & 0.031 \\
\hline Sodium selenite & 0.00914 & Riboflavine & 0.219 \\
\hline HEPES & 4289.4 & Thiamine hydrochloride & 2.1685 \\
\hline Sodium bicarbonate & 1800 & Cyanocobalamine & 0.6865 \\
\hline Calcium chloride & 99.155 & L-Alanine & 16.955 \\
\hline Cupric sulfate (pentahydrate) & 0.00125 & L-Arginine hydrochloride & 147.500 \\
\hline Ferrous sulfate (heptahydrate) & 0.417 & (monohydrate) & \\
\hline Potassium chloride & 277.0 & L-Asparagine (monohydrate) & 21.705 \\
\hline Potassium nitrate & 0.038 & L-Aspartic acid & 21.655 \\
\hline Magnesium chloride & 61.051 & L-Cysteine hydrochloride & 17.560 \\
\hline (hexahydrate) & & L-Glutamic acid & 44.855 \\
\hline Magnesium sulfate & 48.835 & L-Glutamine & 365.0 \\
\hline Sodium chloride & 6052.0 & Glycine & 18.755 \\
\hline $\begin{array}{l}\text { Disodium hydrogen } \\
\text { phosphate }\end{array}$ & 71.0 & $\begin{array}{l}\text { L-Histidine hydrochloride } \\
\text { (monohydrate) }\end{array}$ & 31.480 \\
\hline Monosodium dihydrogen & 62.5 & L-Methionine & 17.240 \\
\hline phosphate & & L-Phenylalanine & 35.480 \\
\hline Zinc sulfate (heptahydrate) & 0.4315 & L-Proline & 37.265 \\
\hline Glucose (anhydrous) & 3151.0 & L-Serine & 26.255 \\
\hline Hypoxanthine & 2.040 & L-Threonine & 53.455 \\
\hline Linoleic acid & 0.042 & L-Tryptophane & 9.020 \\
\hline DL-Thioctic acid & 0.103 & L-Tyrosine & 54.615 \\
\hline Putrescine dihydrochloride & 0.0805 & L-Valine & 52.855 \\
\hline Sodium pyruvate & 110.0 & L-Isoleucine & 54.470 \\
\hline Thymidine & 0.3635 & L-Leucine & 59.060 \\
\hline D-Biotin & 0.01015 & L-Lysine hydrochloride & 91.270 \\
\hline D-Calcium pantothenate & 2.2385 & L-Cystine dihydrochloride & 45.620 \\
\hline Choline chloride & 9.00 & Kanamycin sulfate & 50.0 \\
\hline Folic acid & 2.66 & Phenol red & 8.120 \\
\hline
\end{tabular}

* Growth factor in serum. A 55 to $70 \%$ ammonium sulfate fraction of bovine serum. 
from Wako Pure Chemical Industries, Ltd.

The composition of GIT medium is shown in Table 1.

The medium contains a basal medium (a mixture consisting of an equal volume of Iscove's medium and F12 medium with some modifications), insulin, transferrin, ethanolamine, selenite, and GFS (growth factor in serum, a 55 to $70 \%$ ammonium sulfate fraction of bovine serum).

Fetal bovine serum (FBS). FBS used throughout the present experiments was Bocknek lot No. 378 and was one of the best lots among 30 tested.

Screening of specific antibody activity in the hybridoma supernatant. Indirect membrane immunofluorescence tests were employed for the anti-Hut 78 antibody assay using culture supernatant as the first antibody and FITC conjugated goat anti-mouse $\operatorname{IgG}(\gamma+\mathrm{L})$ (EY Laboratories, San Mateo, CA, USA) as the second. Indirect hemagglutination tests were employed to detect antibody against SRBC. Twenty five $\mu \mathrm{l}$ of the hybridoma supernatant was brought to the wells of a U-bottom microplate, and $25 \mu \mathrm{l}$ of SRBC suspension (adjusted to $2 \times 10^{8} / \mathrm{ml}$ ) was added to each well. After incubation at $37^{\circ} \mathrm{C}$ for 15 min with vibration, the SRBCs were washed with gelatin veronal buffer (GVB) using a microplate centrifuge (Kokusan, H-161, Tokyo) three times. Fifty $\mu 1$ of rabbit anti-mouse IgG (MBL, Nagoya), diluted to $1: 300$ with GVB was added and the plate was vibrated for $15 \mathrm{~min}$. Incubation was carried out at $37^{\circ} \mathrm{C}$ for $60 \mathrm{~min}$, and at room temperature for $60 \mathrm{~min}$. By reading the hemagglutination pattern, the antibody in the hybridoma supernatant was examined.

Determination of fusion frequency. To calculate the lowest number of parental cells required to produce hybrids, a microculture examination, in which only a fraction of microcultures (96-well plate wells) responds with hybrid cell growth, was performed. In this experiment, either SRBC or keyhole limpet hemocyanine (KLH, $100 \mu \mathrm{g}$ emulsified with Freund's complete adjuvant) was used as an immunogen; the immunization schedule was the same as described previously. A graded number of myeloma cells $\left(1,3\right.$ and $10 \times 10^{3}$ cells) and immune spleen cells $\left(1,3\right.$ and $10 \times 10^{4}$ cells) were distributed to each well after cell fusion. As feeder cells, BALB/c thymocytes $\left(1 \times 10^{6}\right.$ cells/well $)$ were added to each well. The growth of hybridoma was determined after 14-day cultivation in GIT-HIAT medium. Since the precursor parental cells forming hybrids per well follow a Poisson distribution, the frequency Fo of wells without growth is given by $\mathrm{Fo}_{\mathrm{O}}=\mathrm{e}^{-\mathrm{N}}$. If $\mathrm{N}$ (average number of precursor cells per well $)=1$, the frequency of nongrowing cultures represents $0.37\left(\mathrm{Fo}_{\mathrm{o}}=\mathrm{e}^{-1}=\right.$ 0.37) (Cianfriglia et al. 1986). The fusion frequency was determined according to this formula and the experimental data.

\section{RESUlTS}

Myeloma cell growth curve. Myeloma cells initially adjusted to $2 \times 10^{5} / \mathrm{ml}$ in GIT or RPMI 1640 plus 10\% FBS (FBS-RPMI) were cultured using $3.5 \mathrm{~cm}$-dishes and the cell number was counted daily (Fig. 1). During the initial 3 days, the myeloma cells cultured in GIT and FBS-RPMI showed similar growth curves. After the first subcultivation, the myeloma cells cultured in GIT proliferated more rapidly than those cultured in FBS-RPMI. On the third day after subcultivation, the mean myeloma cell number of the three cultivations in GIT was $12.6 \times$ $10^{5} / \mathrm{ml}$, whereas the mean cell number of the three cultivations in FBS-RPMI was $7.7 \times 10^{5} / \mathrm{ml}$. The viability of the myeloma cells cultured in GIT was constantly more than $95 \%$. Another $\mathrm{C} 3 \mathrm{H}$ mouse myeloma cell line, TIB 16, also showed much better growth when cultured in GIT than in FBS-RPMI (data not shown).

Results of hybridoma establishment. The results of the hybridoma produc- 


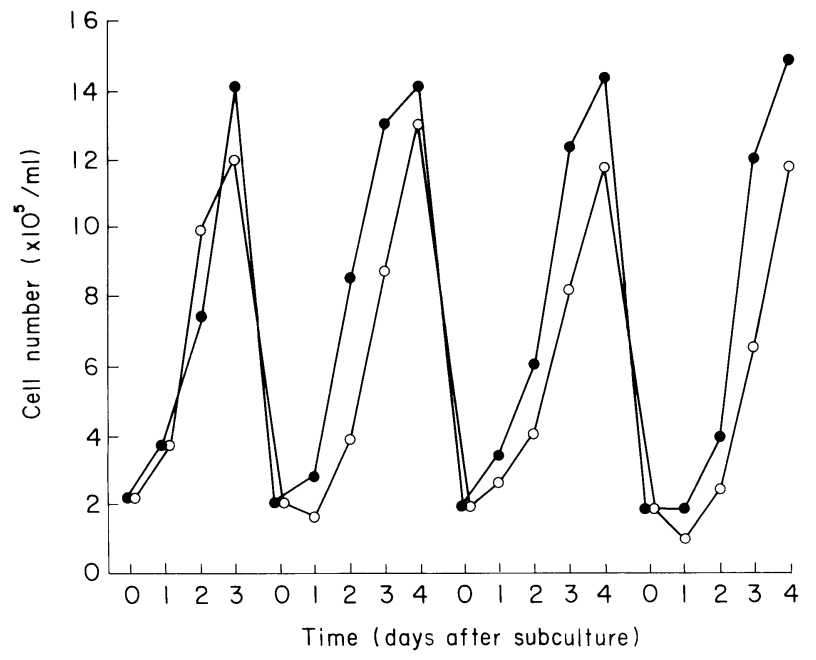

Fig. 1. Growth curve of P3X63Ag8-653 myeloma cells.

Growth of mouse myeloma cells was examined by counting the cell number after subculture daily. Myeloma cells initially adjusted to $2 \times 10^{5} / \mathrm{ml}$ in either GIT medium (-) or RPMI 1640 plus 10\% FBS (_-) were cultured using 6-cm diameter dish for 3 or 4 days. Myeloma cells cultured in GIT were subcultured again in the GIT medium; myeloma cells cultured in RPMI 1640 plus $10 \%$ FBS were also subcultured in RPMI 1640 plus $10 \%$ FBS.

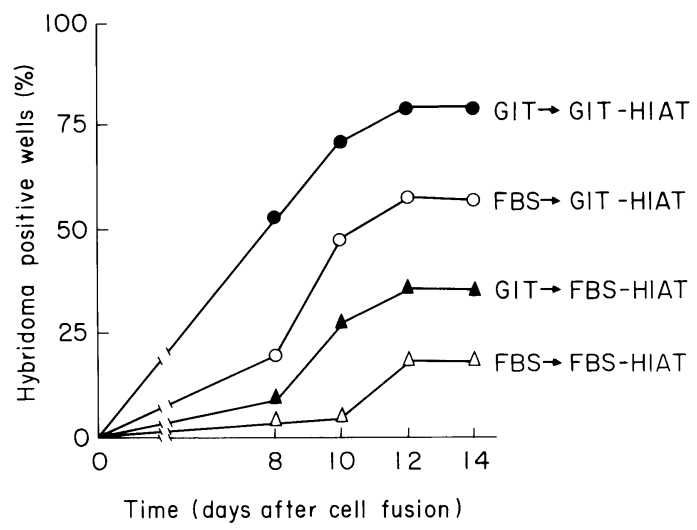

Fig. 2. Effect of culture medium on hybridoma production.

Effect of culture medium on hybridoma production was examined by four culture schedules. 1) Myeloma cells cultured in GIT served for cell fusion, and hybridoma cells were selected in the GIT-HIAT medium. 2) Myeloma cells cultured in RPMI 1640 plus 10\% FBS served for cell fusion, and hybridoma cells were selected in GIT-HIAT medium. 3) Myeloma cells cultured in GIT served for cell fusion, and hybridoma cells were selected in the RPMI 1640-FBS-HIAT medium. 4) Myeloma cells cultured in RPMI 1640 plus 10\% FBS served for cell fusion, and hybridoma cells were selected in RPMI 1640-FBS-HIAT. The hybridoma colony positive wells were checked during the course of cultivation after cell fusion, and the percentage of colony positive wells was scored among the seeded 60 wells for each group. In these cell fusions, $1 \times 10^{5}$ myeloma cells and $1 \times 10^{6}$ spleen cells immunized with $\mathrm{SRBC}$ were delivered to each well. 
TABLE 2. Summary of cell fusion experiment

\begin{tabular}{|c|c|c|c|c|}
\hline Culture medium & $\begin{array}{l}\text { Fusion } \\
\text { exp. }\end{array}$ & $\begin{array}{c}\text { Colony positive } \\
\text { wells / seeded } \\
\text { wells }{ }^{2}\end{array}$ & $\begin{array}{l}\text { Number of } \\
\text { wells with } \\
\text { specific } \\
\text { antibody }\end{array}$ & $\begin{array}{l}\text { Antigen } \\
\text { immu- } \\
\text { nized }\end{array}$ \\
\hline \multirow{3}{*}{$\begin{array}{l}\text { Myeloma cultured in } \\
\text { GIT medium }\end{array}$} & 1 & $115 / 120(95.8 \%)^{* *}$ & $81 / 115(70.4 \%)$ & Hut 78 \\
\hline & 2 & $75 / 80(93.8 \%)^{* *}$ & NT & Hut 78 \\
\hline & 3 & $64 / 70(91.4 \%)^{* *}$ & $\mathrm{NT}$ & Hut 78 \\
\hline \multirow{3}{*}{$\begin{array}{l}\text { Hybridoma cells selected in } \\
\text { GIT + HIAT medium }\end{array}$} & 4 & $48 / 60(80.0 \%)^{* *}$ & $48 / 48(100.0 \%)$ & SRBC \\
\hline & 5 & $115 / 120(95.8 \%)^{* *}$ & $115 / 115(100.0 \%)$ & SRBC \\
\hline & 6 & $112 / 120(93.3 \%)^{* *}$ & $108 / 112(96.4 \%)$ & SRBC \\
\hline \multirow{3}{*}{$\begin{array}{l}\text { Myeloma cultured in } \\
\text { RPMI- } 1640+\text { FBS }\end{array}$} & $1^{\prime}$ & $21 / 55(38.2 \%)$ & $10 / 21(47.1 \%)$ & Hut 78 \\
\hline & $2^{\prime}$ & $25 / 80(31.3 \%)$ & NT & Hut 78 \\
\hline & $3^{\prime}$ & $20 / 70(28.6 \%)$ & NT & Hut 78 \\
\hline \multirow{3}{*}{$\begin{array}{l}\text { Hybridoma cells selected in } \\
\text { RPMI- } 1640+\text { FBS + HIAT }\end{array}$} & $4^{\prime}$ & $11 / 60(18.3 \%)$ & $11 / 11(100.0 \%)$ & $\mathrm{SRBC}$ \\
\hline & $5^{\prime}$ & $15 / 120(12.5 \%)$ & $14 / 15(93.3 \%)$ & SRBC \\
\hline & $6^{\prime}$ & $29 / 120(24.2 \%)$ & $21 / 29(72.4 \%)$ & SRBC \\
\hline
\end{tabular}

1 Spleen cells from the same source were used for the cell fusion in experiment 1 and $1^{\prime}$. Similarly in exp. 2 and $2^{\prime}$, in exp. 3 and $3^{\prime}$, in exp. 4 and $4^{\prime}$, in exp. 5 and $5^{\prime}$, and in exp. 6 and $6^{\prime}$, spleen cells from the same source were served for cell fusion.

2 Myeloma cells and spleen cells were mixed at a ratio of $1: 10$, and fused as noted in Materials and Methods. After cell fusion, $0.2 \mathrm{ml}$ of cell suspension consisting of $1 \times$ $10^{5}$ myeloma cells and $1 \times 10^{6}$ spleen cells was cultured in every well of a 96 -well culture plate.

NT, not tested.

${ }^{* *} p<0.01$ against the number of hybridoma positive wells in non-GIT culture.

tion are summarized in Table 2. In fusions from No. 1 to No. 6, the myeloma cells propagated in GIT served for cell fusion; the GIT-HIAT medium was used for hybridoma selection (GIT $\Rightarrow$ GIT-HIAT). In fusions from No. $1^{\prime}$ to No. 6', the myeloma cells propagated in FBS-RPMI served for cell fusion, and FBS-HIAT was used for hybridoma selection (FBS $\Rightarrow$ FBS-HIAT).

The spleen cells used for fusions No. 1 and No. 1' were obtained from the same immunized mice. Similarly, the same spleens were used for cell fusion in Exp. 2 and $2^{\prime}, 3$ and $3^{\prime}, 4$ and $4^{\prime}, 5$ and $5^{\prime}$, and 6 and $6^{\prime}$, respectively. More than $80 \%$ of total seeded wells showed hybridoma colony growth in the fusion experiments from No. 1 to No. 6 irrespective of the immunized antigens. In fusion experiments from No. $1^{\prime}$ to No. 6 ', while hybridoma growth was observed, the percentage of growth positive wells ranged from $12.5 \%$ to $38.2 \%$; much lower than in fusion experiments from No. 1 to No. 6 . In accordance with the above results, usually more than 3 hybridoma colonies were observed in a single well of the fusion experiments from No. 1 to No. 6 . In the case of fusion experiments from No. $1^{\prime}$ to No. $6^{\prime}$, smaller numbers of hybridoma colonies ( 1 to 3 colonies) were observed in 
each hybridoma positive well.

Specific antibody production was tested by either indirect membrane immunofluorescence tests in the case of Hut 78, or indirect hemagglutination method using a U-bottom microtest plate when immunized with SRBC. In fusion experiment No. 1, 81 wells $(70.4 \%)$ of 115 hybridoma positive wells reacted positively with Hut 78 cells. Ten wells $(47.1 \%$ ) of 21 hybridoma positive wells showed positive antibody reaction in fusion No. $1^{\prime}$.

When SRBC were immunized, every hybridoma positive well in No. 4, 5, and 4 fusions showed positive SRBC hemagglutination. In fusion No. 6, more than $90 \%$ of the hybridoma positive wells reacted with SRBC; a slightly lower percentage $(72.4 \%$ ) of the hybridoma positive wells showed hemagglutination tests in fusion No. 6'.

Effect of four culture schedules on the hybridoma establishment. To obtain the optimal culture schedule for hybridoma production, four culture schedules were tested. The first consisted of the propagation of myeloma cells in the GIT medium and selection of hybridoma cells in the GIT-HIAT medium (GIT $\Rightarrow$ GIT-HIAT). The second consisted of the myeloma cells propagated in the FBS medium and selection in GIT-HIAT. The third consisted of the myeloma cells propagated in the GIT medium and selection in FBS-HIAT. The fourth consisted of the use of the myeloma cells in FBS-RPMI and selection in FBS-HIAT (FBS $\Rightarrow$ FBS-HIAT). In these four schedules, cell fusion was done using the same pooled spleen cells from the mice immunized with SRBC and hybridoma colony formation was recorded during the course of cultivation after cell fusion (Fig. 2).

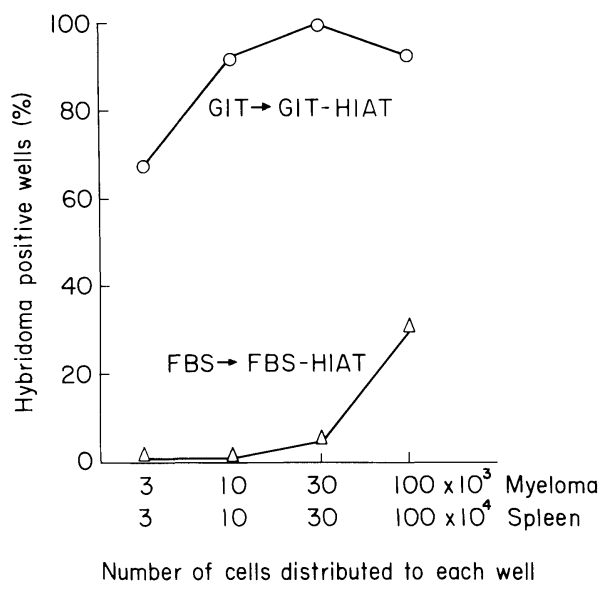

Fig. 3. Checking optimal condition of hybridoma selection by changing the cell numbers distributed to each well.

The graded number of myeloma cells and spleen cells immunized with SRBC as documented in the text were distributed to each well and cultured in either GIT-HIAT or RPMI 1640-FBS-HIAT. The percentage of hybridoma positive wells was scored among the distributed 48 wells. 
The best result was obtained by the first schedule ; the final percentage of colony positive wells was $80 \%$. The second schedule (FBS $\Rightarrow$ GIT-HIAT) showed $58.3 \%$ colony positive wells ; the third (GIT $\Rightarrow$ FBS-HIAT) showed $36.7 \%$ colony positive wells; and the worst result $(18.3 \%)$ was obtained by the fourth (FBS $\Rightarrow$ FBS-HIAT).

These results indicated that both cultivation of myeloma cells using GIT medium before cell fusion and the selection of hybridoma using GIT-HIAT medium after cell fusion were important to obtain the best fusion efficiency.

Estimation of optimal cell number per well for hybridoma production. Because too many cells sometimes cause culture conditions to deteriorate, optimal cell number in one well for the hybridoma colony formation was tested. Various numbers of myeloma cells and spleen cells after cell fusion were distributed to each well of a 96-well plate. As shown in Fig. 3,48 of distributed 48 wells $(100 \%)$ showed hybridoma colony production when $3 \times 10^{4}$ myeloma cells and $3 \times$ $10^{5}$ spleen cells were cultured in each well after cell fusion (GIT $\Rightarrow$ GIT-HIAT). Forty five of 48 wells $(93.8 \%)$ showed hybridoma production when $1 \times 10^{4}$ myeloma and $1 \times 10^{5}$ spleen cells or $1 \times 10^{5}$ myeloma and $1 \times 10^{6}$ spleen cells were distributed to each well in GIT $\Rightarrow$ GIT-HIAT. A small number of myeloma cells $\left(1 \times 10^{3}\right)$ and spleen cells $\left(1 \times 10^{4}\right)$ also produced hybridoma colonies, however, the percentage of colony positive wells decreased $(68.8 \%)$. Fifteen of 48 wells $(31.3 \%)$ produced hybridoma colonies in FBS $\Rightarrow$ FBS-HIAT medium when $1 \times 10^{5}$ myeloma and $1 \times 10^{6}$ spleen cells were distributed to the wells. Only 3 of 48 wells produced hybridoma colonies (FBS $\Rightarrow$ FBS-HIAT) when $3 \times 10^{4}$ myeloma cells and $3 \times 10^{5}$ spleen cells were distributed to the wells. Fewer than $1 \times 10^{4}$ myeloma cells and $1 \times 10^{5}$ spleen cells per well produced no hybridoma colony $(\mathrm{FBS} \Rightarrow$

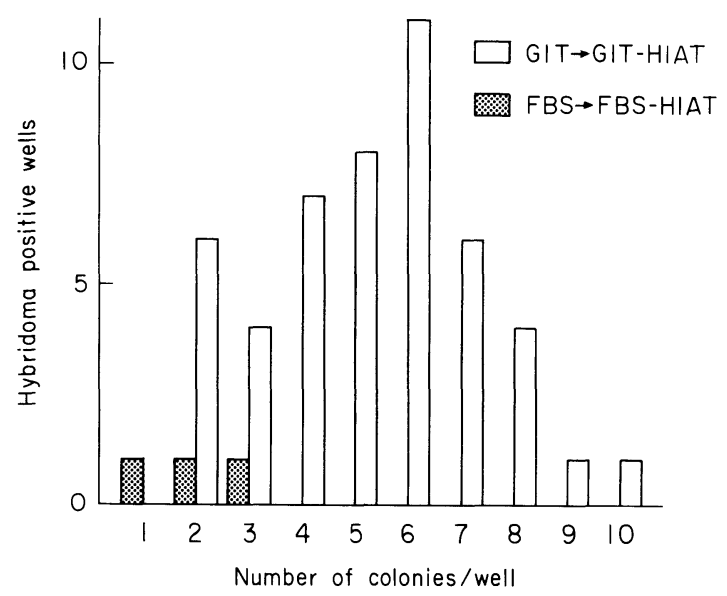

Fig. 4. Histogram of hybridoma colonies.

The number of hybridoma colonies was counted in the fusion experiment as shown in Fig. 3. The number of hybridoma positive wells is scored on the ordinate, and the number of colonies/well is expressed on the abscissa. 


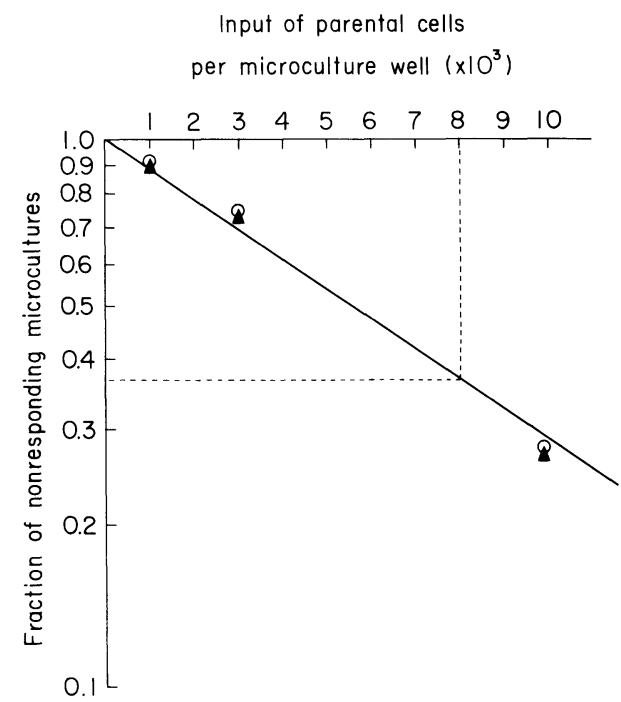

Fig. 5. Limiting dilution of parental myeloma cells to calculate the fusion frequency. The input of myeloma cells for each cell dilution was calculated as the values found in 60 wells. $\bigcirc \mathrm{SRBC} ; \boldsymbol{\wedge} \mathrm{KLH}$ used as immunogen.

\section{FBS-HIAT).}

Counting of colony number in the well. When $3 \times 10^{4}$ myeloma cells and $3 \times$ $10^{5}$ spleen cells were distributed to each well (GIT $\Rightarrow$ GIT-HIAT), all the wells showed hybridoma colony production (Fig. 3). Colony counting in the well was done using an inverted microscope (total; 48 wells). As shown in Fig. 4, the number of colonies in the wells ranged from 2 to 10 ; the mean number was 5.23, much more than observed in FBS $\Rightarrow$ FBS-HIAT medium.

Fusion frequency determination. Interpolating at the level of $\mathrm{Fo}_{\mathrm{o}}=0.37$ (Fig. 5), which corresponds to one hybridoma/well, Poisson analysis demonstrated that the frequency of "precursor" hybrid cell was $1 / 8,000$ under the conditions stated when either SRBC or KLH was used as an immunogen.

\section{Discussion}

Though numerous hybridomas have been established, cell fusion efficiency remains unstable. In our 10 most recent fusion experiments, the mean percentage of hybridoma positive wells of seeded wells was $17.6 \%$, ranging from $0.83 \%$ to $34.4 \%$. To improve the fusion efficiency, many investigators have proposed revision of cell fusion methods, such as the selection of a good lot of fetal bovine serum, the use of low toxic polyethylene glycol (PEG), the use of feeder cells, an electro-cell fusion method, enhancing cell attachment by lectins, and so on (Westerwoudt 1985; Cianfriglia et al. 1986; Long et al. 1986; Ransom 1986). In the present experiments, described here, marked and stable improvement of cell fusion efficiency was obtained by using the GIT medium, developed quite recently. 
More than $80 \%$ of seeded wells were hybridoma colony positive irrespective of the antigens, and the hybridomas selected by using the GIT-HIAT medium produced specific antibody quite well, indicating that the desired hybridoma clones can be obtained much easier than before using of the GIT medium.

When $3 \times 10^{4}$ myeloma cells and $3 \times 10^{5}$ spleen cells were seeded in a well, many hybridoma colonies (mean 5.23, range 2 to 10 colonies) were observed using the GIT medium for myeloma cultivation and the GIT-HIAT medium for the subsequent selection of hybridoma cells.

When specific efficiency of fusion was defined as the number of specific antibody-producing wells $\times 100$ per $10^{6}$ spleen cells according to Erkman (Erkman et al. 1987), the present result in the case of seeding $3 \times 10^{4}$ myeloma cells to each well ranged over 300 .

From these results, we expected that fewer than $10^{4}$ parental myeloma cells contained one "precursor" hybrid cell. To confirm this, a graded number of myeloma cells and spleen cells were distributed to a 96 -well microplate after cell fusion in the same as the limiting dilution method. The fusion frequency was calculated by plotting the fraction of nonresponding microcultures vs. input of parental cells per well. About $8 \times 10^{3}$ parental myeloma cells contained one "precursor" hybrid cell when SRBC or KLH was used as an immunogen (Fig. 5). This efficiency is much better than those reported previously (Cianfriglia et al. 1986 ; Lane et al. 1986 ; Long et al. 1986).

Another advantage of the GIT medium is that it has very little lot-to-lot variation (data not shown). We have used six lots of GIT medium so far, and have found that hybridoma production is very constant. In addition, B cell hybridoma in GIT produced about twice as much antibody as hybridoma cultured in RPMI 1640 plus 10\% FBS when the same hybridoma was compared in two different culture media. We used GIT medium to clone hybridomas by limiting dilution method and found that cloning efficiency also increased as compared with RPMI 1640 plus 10\% FBS.

It is not completely clear why the GIT medium is good for hybridoma production. One reason is that the medium is suitable to propagate myeloma cells. It was developed by checking mainly the growth of myeloma cells and hybridoma cells as an index. Unbelievably good viability of myeloma cells was observed in the GIT medium; more than $95 \%$ viability constantly.

As shown in Fig. 2, GIT is also favorable for hybridoma selection. The growth factor in serum (GFS), which was added in GIT, is composed of $55 \%$ to $70 \%$ ammonium sulfate fraction of bovine serum and is devoid of bovine $\gamma$ globulin. It follows that the GIT medium is completely free from natural antibody that may sometimes hinder cell function. Murakami and co-workers reported ethanolamine as being essential for hybridoma growth under serum-free medium, and the ethanolamine in the GIT medium must also play an important role in hybridoma production (Murakami et al. 1982; Kovar and Franek 1986). 
Yabe et al. (1986) have described the development of a new serum-free medium, designated as NYSF which is a very peculiar and interesting culture medium for selective proliferation of B cell hybridomas. This NYSF medium is a 1:1 mixture of RPMI 1640 and MEM supplemented with hypoxanthine, thymidine, insulin, dihydroxyethylglycine, transferrin, ethanolamine, selenite, amino acids, and so on. In NYSF medium, mouse myeloma cells do not grow and only hybridoma cells can survive. For this reason, addition of HAT is not necessary and enhanced hybridoma production has been reported. We have used the NYSF medium and found that the efficacy of the medium for hybridoma production is similar to that of GIT-HIAT, provided that P3X63Ag8-653 myeloma cells are propagated in GIT before cell fusion. The utility of the NYSF medium is limited only when myeloma cells of near diploid type are used as partner cells. We used another myeloma cell line, Sp-2, which is near tetraploid type and found that enhanced hybridoma production was also observed by using the GIT medium. The usefulness of the GIT medium in hybridoma production is not limited to P3X63Ag8-653 cells but can be also applied to other myeloma cells. In our preliminary experiements, human myeloma cells grew more rapidly in the GIT medium than in the RPMI 1640 medium enriched with 10\% FBS. The use of the GIT medium should greatly improve human-human hybridoma production.

\section{Acknowledgments}

This work was partially supported by Grant for Scientific Research No. 60870021 from the Ministry of Education, Science and Culture, Japan.

\section{References}

1) Cianfriglia, M., Mariani, M., Armellini, D., Massone, A., Lafata, M., Presentini, R. \& Antoni, G. (1986) Methods for high frequency production of soluble antigen-specific hybridomas: Specificities and affinities of monoclonal antibodies obtained. Meth. Enzymol., 121, 193-210.

2) Erkman, L., Soldati, G., James, R.W. \& Kato, A.C. (1987) Partial purification of lymphoblasts after in vitro immunization increases the yield in Ig-producing hybridomas. J. Immunol. Meth., 98, 43-52.

3) Kovar, J. \& Franek, F. (1986) Serum-free medium for hybridoma and parental myeloma cell cultivation. Meth. Enzymol., 121, 277-292.

4) Köhler, G. \& Milstein, C. (1975) Continuous cultures of fused cells secreting antibody of predefined specificity. Nature (Lond.), 256, 495-497.

5) Lane, R.D., Crissman, R.S. \& Ginn, S. (1986) High efficiency fusion procedure for producing monoclonal antibodies against weak immunogens. Meth. Enzymol., 121, 183-192.

6) Long. W.J., McGuire, W., Palombo, A. \& Emini, E.A. (1986) Enhancing the establishment efficiency of hybridoma cells. Use of irradiated human diploid fibroblast feeder layers. J. Immunol. Meth., 86, 89-93.

7) Murakami, H., Masui, H., Sato, G.H., Sueoka, N., Chow, T.P. \& Kano-Sueoka, T. (1982) Growth of hybridoma cells in serum-free medium: Ethanolamine is an essential component. Proc. nat. Acad. Sci. USA, 79, 1158-1162. 
8) Ransom, J.H. (1986) Endotherial cell growth supplements for promoting the growth of monoclonal antibody-producing hybridoma cells. Meth. Enzymol., 121, 293-295.

9) Sasai, S., Umemoto, S. \& Fujimoto, T. (1985) Establishment of a medium for mass culture of mammalian cells. Third International Cell Culture Congress Abstract. (Sendai), pp. 46.

10) Westerwoudt, R.J. (1985) Improved fusion methods. IV. Technical aspects. $J$. Immunol. Meth., 77, 181-196.

11) Yabe, N., Matsuya, Y., Yamane, I. \& Takada, M. (1986) Enhanced formation of mouse hybridomas without HAT treatment in a serum-free medium. In Vitro cell. develop. Biol., 22, 363-368. 